Article

\title{
Land, Income and Land-Use Diversification in Khyber Pakhtunkhwa Province of Northern Pakistan
}

\author{
Siddique Ullah Baig ${ }^{1 *}$, Syed Muhammad Jibran Shah², Bahadar Nawab Khattak ${ }^{3}$ \\ 1 High Mountain Research Center, Department of Development Studies, COMSATS University Islamabad, \\ Abbottabad Campus, Pakistan \\ 2 Department of Development Studies, COMSATS University Islamabad, Abbottabad Campus, Pakistan \\ 3 Department of Development Studies, COMSATS University Islamabad, Abbottabad Campus, Pakistan \\ * Correspondence: sbbaig@ ciit.net.pk; Tel.: +92-342-526-4393
}

\begin{abstract}
The natural and man-made landscape settings in the Khyber Pakhtunkhwa (KPK) province of Northern Pakistan have significantly changed in the last decade due to increasing demands of urbanized populace, migration, two major natural disasters, and climate change. The aim of this study is to analyze land possession, income and land-use diversification of KPK administered Charsadda district. Field data is collected through a sample survey. Furthermore, freely available Landsat 7 satellite images are used to classify land-use classes (e.g. vegetation, builtup) for two different years (e.g. 2005 and 2017) for cross-verification and comparison. The highest $45 \%$ of $80 \%$ land-owners occupy land-area between 1-10 hectares. Annually, the highest $57.5 \%$ of the total farmers / employed in-habitants of surveyed regions earn more than Rs. 100,000 or $~ \$ 970$ from agriculture activities. About $41.9 \%$ land-area covered by agricultural-land is transformed into built-up area since 2007, which is attributed to the increasing demand for buildings and commercial markets. The highest diversification is reported in Naguman area of Charsadda district followed by Rajjar and Niami. Population growth and huge migration of displaced persons from neighboring tribal areas are likely to be few factors which contributed to such a drastic change in land-use pattern since 2007 to 2017. Urgent attention of the policy makers, agricultural experts and society is required to minimize land degradation and to thwart further agricultural-land loss.
\end{abstract}

Keywords: Land-use; satellite imagery; agriculture

\section{Introduction}

In Pakistan, growing urbanization pattern is witnessed over the past many years due to huge migration of families from rural areas to the cities. According to the World Bank, by the year -2020, more than $50 \%$ of the Pakistan's total populace will migrate to the cities or rural areas will become urbanized [15]. Due to this huge migration, land-use and land-cover, which are the two important components of natural environment, are likely to be disturbed. In this work, land-cover describes land-area occupied by natural entities like forest, rivers, mountains and glaciers. Land-use includes the administration and adjustment of the natural setting into built-environment (e.g. settlements, habitats, agriculture fields, grasslands) [2]. Land-use change is one of the most important arenas of man-made environmental transformation [8]. A significant research work is available on land-use and land-cover and its effects on landscapes [6]; [7]. What are the driving forces for these significant land-use changes need to be investigated. In the past, urbanization and industrialization were considered to be major factors, which play a vital role in land-use transformations [9]. A comparison of driving forces responsible for transformation of agricultural-land in many under-developed, developing and developed countries is undertaken [1]. In developing world like China, industrialization and globalization are considered to be two factors which trigger land-use change apart from other human interventions [4]. However, the driving forcing behind land-use changes in developing countries (e.g. India and Pakistan) are anthropogenic or human interventions on natural 
environment [5]. Therefore, human actions or interventions other than natural forces are likely to be prime causes of the modern-day transformation of land.

About $41 \%$ of land-area of Khyber Pakhtunkhwa (KPK) is cultivable [11] as compared with 50\% cultivable waste land [14]. About 22\% of the total Gross Domestic Product (GDP) of KPK province of Northern Pakistan comes from agriculture-related business activities [10]. The statistics presented in this report shows that about $44 \%$ employed labor-force of the province is engaged with agriculture and nearly $80 \%$ population relies on agriculture and meet their both ends. However, the natural settings especially in rural areas of KPK have significantly changed in the preceding decade due to the occurrence of a number of major natural disasters (e.g. torrential rains of 2010, earthquake 2005), rising temperature and fluctuating monsoon rains.

The rate of land-use transformation from cultivable to non-cultivable is reported to be higher in KPK as compared with other provinces in Pakistan. Urbanization is at the peak due to influx of internally displaced persons from FATA and Afghan refugees, driven by armed conflicts in neighboring areas (e.g. FATA and Afghanistan), political instability, violence and other natural disasters. This drastic change has transformed agricultural land to settlements resulting in the conversion of more cultivable-land to non-cultivable settings [16]. The positive aspect of this migration is reflected in commercial market expansion, flourished housing schemes and business activities. On the other hand, cultivable land reduced considerably. The current state of land-use changes is not known yet. Therefore, this study aims is to analyze decadal land-use change analysis of Charsadda district administered by KPK province of Northern Pakistan since 2005 to 2017 through space and field-based investigations so that agriculture loss could be gauged. Geographic Information Systems (GIS) is considered to be a good tool to detect land-use change [17]; [18]. Therefore, this study employs GIS and classification of remote sensing imagery to detect these changes. GIS helped us in many stages of data capturing, analysis and presentation of geo-data while remote sensing in the progression of finding the land-use change detection for two years (2005 and 2017). In order to co-relate income and land-possession information with land-use changes, fieldbased sample survey is conducted. Freely available satellite images are used to classify land-use classes for two different years (e.g. 2005 and 2017) and for cross-verification and comparison.

\section{Study Area}

This study was carried out on landscapes of five sub-regions (e.g. Rajjar, Utmanzai, Naguman, Niami) of Charsadda district which lies entirely within the Khyber Pakhtunkhwa province of Northern Pakistan. Map of the study area administered by KPK province of Northern Pakistan is shown in Figure 1. The spatial domain of the study area is $34^{\circ} 20^{\prime}$ and $34^{\circ} 27^{\prime} \mathrm{N}$ latitudes and $71^{\circ} 21^{\prime}$ and $71^{\circ} 56^{\prime}$ E longitudes. Charsadda district occupies a land-area of $\sim 1000 \mathrm{~km}^{2}$ (19\% urban, 89\% rural) with a population of 1.616 million [19]. Geographically Charsadda is located at the south of Peshawar district, Mohmand Agency of the Federally Administered Tribal Areas (FATA) in the west, Mardan district in the east and Malakand Division in the north. The natural setting of Charsadda is similar to valley plains. In this district, based on criteria provided by [10], access of people to food stands at $=0.55$ index, monthly income of house hold $\sim<1.25 \$$ / per day, food absorption/consumption at $=0.71$ index. The land is fertile and best suitable for the agricultural productivity therefore majorly of inhabitants are associated with the agricultural industry. A sample survey is undertaken in certain sub-regions (e.g. Rajjar, Utmanzai, Naguman, Niami) of district Charsadda. The chosen sub-regions of Charsadda district are agriculture dependent and accessible to surrounding markets especially of Peshawar city (capital of Khyber Pakhtunkhwa province of Pakistan). 
$70^{\circ} 0^{\circ} 0^{\circ} \mathrm{E}$ $75^{\circ} 0^{\circ} 0^{\prime \prime}$

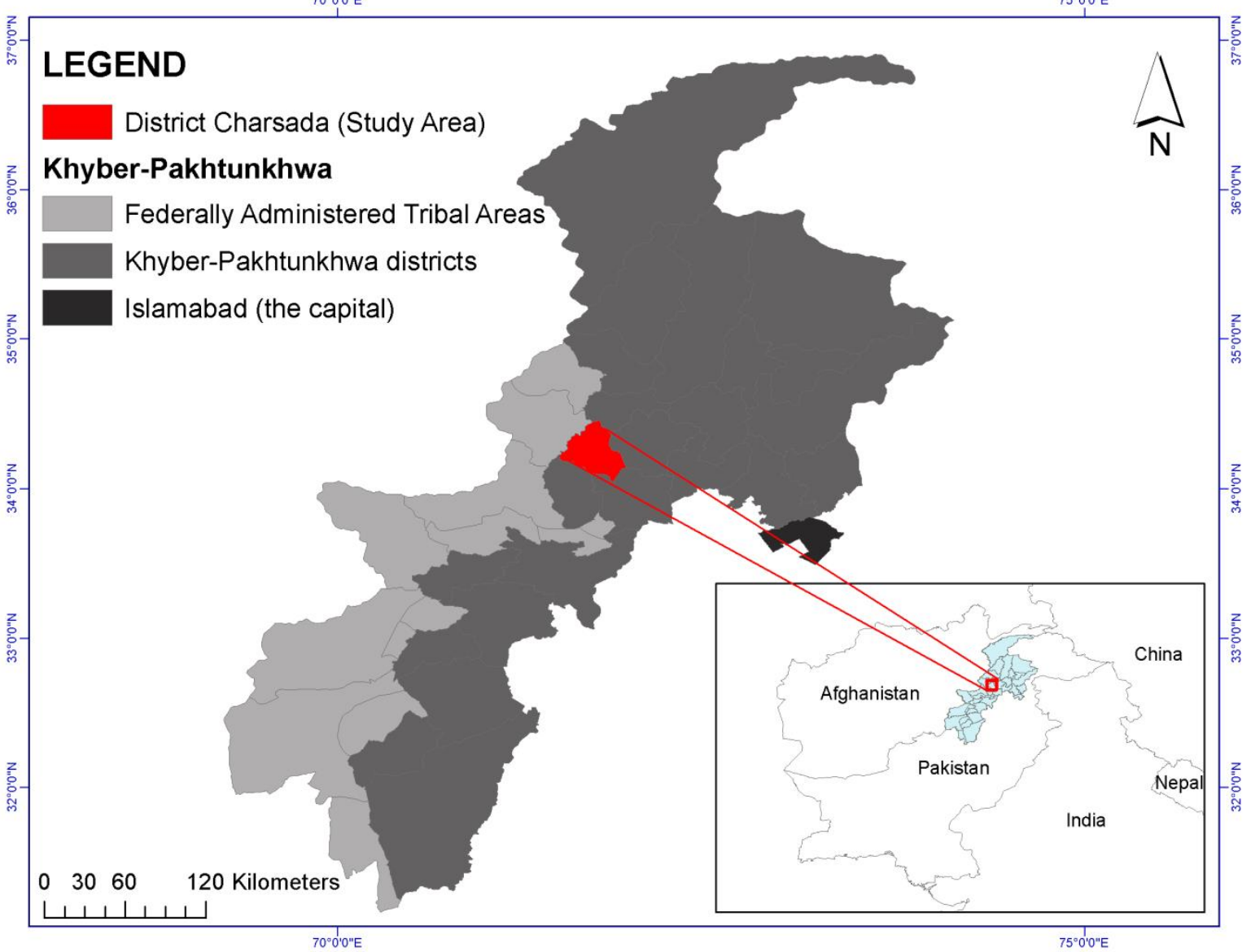

Figure 1. Map of the study area (district Charsadda) within the jurisdiction of Khyber Pakhtunkhwa (KPK) province of Northern Pakistan. Dark grey areas represent settled districts of KPK while light grey represents Federally Administered Tribal Areas (FATA).

\section{Ground Survey, Materials and Methods}

A sample survey is undertaken for data collection in the month of October, 2017. Primary data about land possession, income range and land-use patterns provided by the head of households are collected from 40 farmers / landowners through field-visits by using a questionnaire. The questionnaire comprised of open and close-ended questions. Specially-narrated questions about change in the land-use patterns over a period of ten years are asked from interviewees. Majority of these respondents are having their own land ranging from 1 to several hectares. In this work, these respondents are called 'land holders'. Those who have little land (less than 1 hectare) are actively participating in the agricultural production activities or in other words, work as servants for other land-owners having bigger portions of land. Information about status of the land currently they have or have been a decade ago in reported in 'land possession' category. Information about land-use administration and adjustment of the natural setting into built-environment (e.g. settlements, habitats, agriculture fields, grasslands) is collected. The collected data is stored in SPSS database and interpreted. For this purpose, descriptive statistics is analyzed in percentage and graphically while inferential statistics is applied to determine the difference between values of variables.

[12] and [13] revealed that the (land-use/land-cover) change analysis can be measured by applying remote sensing methods. However, unsupervised classification method has some limitations due to unguided estimations. In this work, satellite imagery as secondary data is used for cross verification and land-use change analysis. Object-based classification method is applied to detect changes in land-use over a period of twelve years (2005-2017). ArcMapVersion-10.2 (Desktop) application is used to classify satellite imagery and pixel-based analysis. There were three reasons for 
using Landsat 7 imagery (1) The GeoTIFF format of Landsat 7 was available with geographic coordinates referenced to the WGS84 geoid and minimum clouds. Therefore, it easily overlapped with GIS boundary of Charsadda district and its sub-regions which were geo-referenced with the same WGS84.

\section{Results and Analysis}

\subsection{Land, income and land-use diversification based-on field-data}

\subsubsection{Land}

Land possession is considered to be major driving force which guarantees food accessibility to the households in rural areas of Khyber Pakhtunkhwa (KPK). This study shows that about 80 percent inhabitants of Charsadda own land as compared with $20 \%$ who do not maintain land-ownership shown in Figure 2 (a). As shown in Figure 2 (b), the highest $45 \%$ of these $80 \%$ land-owners occupy the second smallest portions of the land between 1-10 hectares. About 20\% land-owners occupy landarea between 10-20 hectares and same percentage between less than 1 hectare followed by $15 \%$ between 20-30 hectares.

No Land Owner

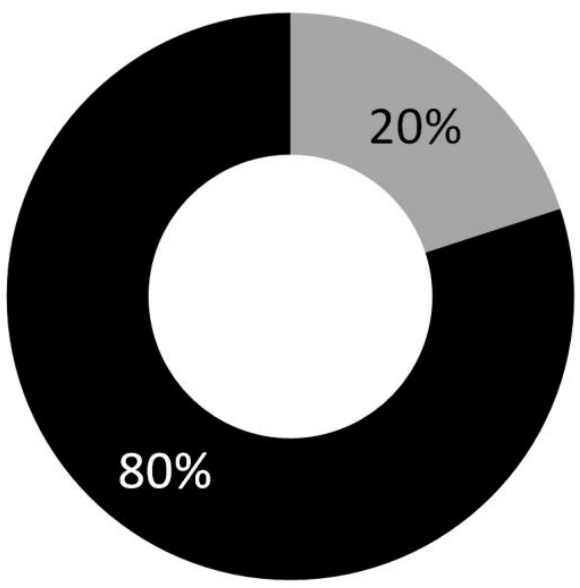

(a)

\section{Less than 1}

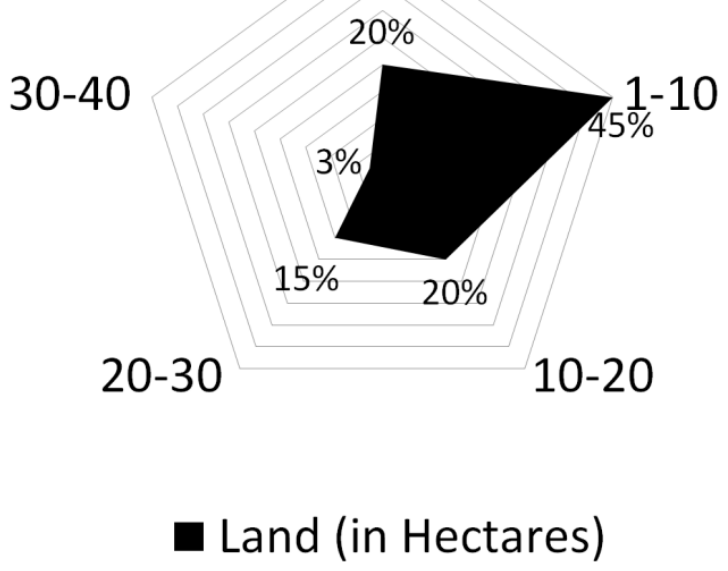

(b)

Figure 2. (a) Percentage distribution of land-owners; (b) Percentage distribution of land-owners occupying landarea (in hectare)

\subsubsection{Land-use status}

Land-use diversification in Charsadda district based on field-data for two years between 2007 and 2017 are presented in the Figure 3. The x-axis of graph describes the name of the land-use type (e.g. Agriculture, Built-up and other) while percentage distribution of covered-area (in \%) appears on the $y$-axis for the years (i.e. 2007 and 2017). The scale/\% in $y$-axis of graph is organized in an equal interval of $20 \%$. Overall, a drastic decreasing trend is reported in the 'agriculture' extent of Charsadda indicating a decrease of $41.9 \%$ while built-up area (e.g. buildings, non-building structures used for housing and commercial activities) increased by 38.6\% during 2007-2017. Furthermore, extent of barren land increased by $13.3 \%$ in a decade. This huge transformation of agriculture land to built-up area is observed to be higher in those regions of Charsadda which are accessible through nearby metalled-roads. 


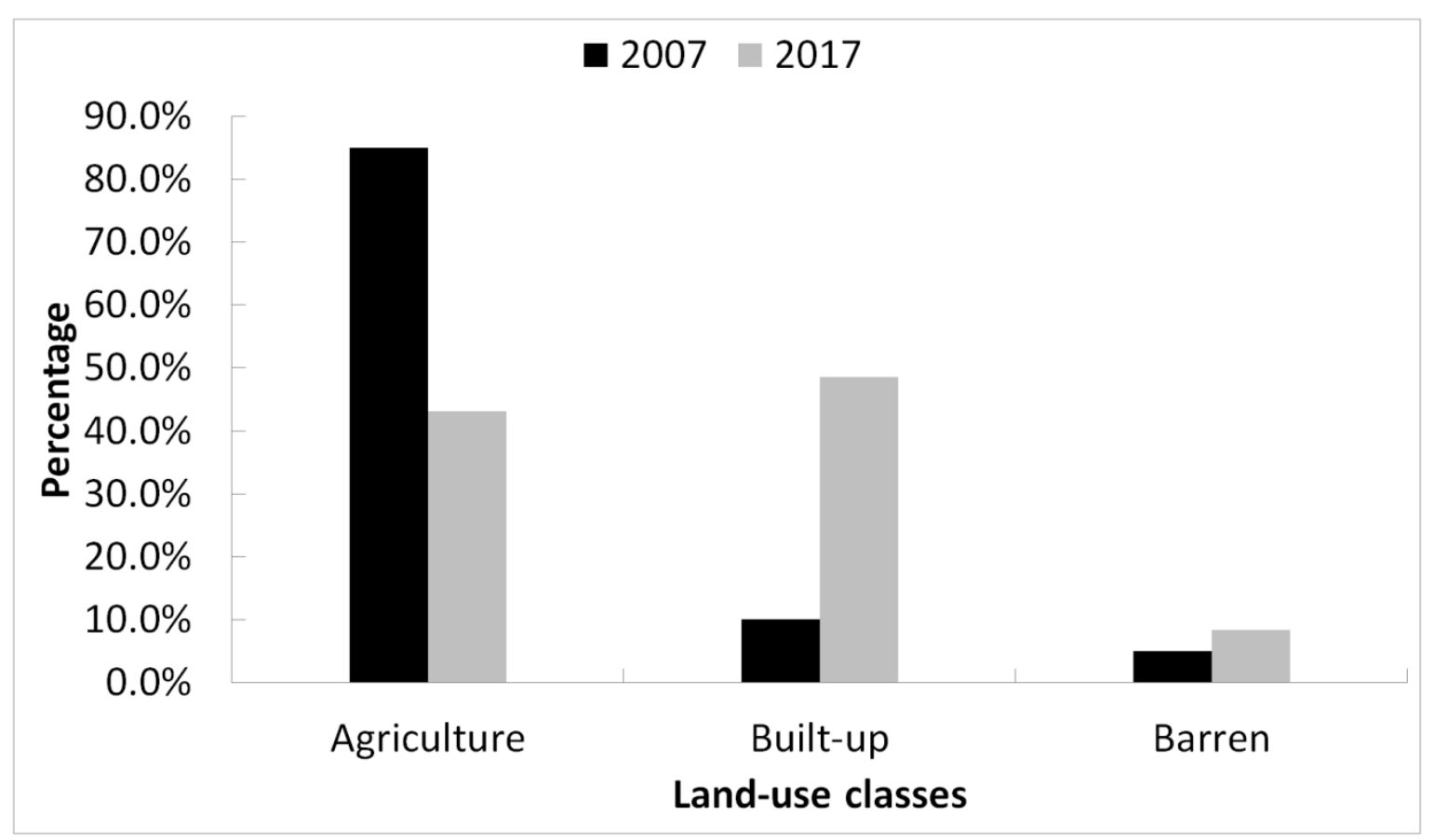

Figure 3. Percentage distribution of land-use diversification in Charsadda district based on field-data for two years between 2007 and 2017.

\subsubsection{Income and sources}

Agricultural land is considered to be one of the major resources of Charsadda district for income generation. Income and sources (agriculture and commercial activities) of income are presented in the Figure 4. The $x$-axis of graph describes income-range (in Pakistani Rupees, where $\$ 1=115$ Pak Rupee) obtained from two income generating industries (e.g. agriculture and commercial) while percentage distribution of farmers / land-owners (in \%) appears on the $y$-axis. The scale/\% in $y$-axis of the graph is organized in an equal interval of $10 \%$. Annually, the highest percentage i.e. 57.5\% of the total farmers / employed in-habitants of surveyed regions earn more than Rs. 100,000 or $\sim 970$ (\$1 = Rs. 115) from 'agriculture" followed by 20.0\% between Rs. 50,000-100,000 or $\sim 435$ to $\sim 970$. About $17.5 \%$ employed in-habitants engaged with agriculture sector do not earn any income from this industry. This shows that either they are un-paid family helpers or working for food. The highest percentage i.e. $32 \%$ employed persons engaged with commercial activities do not earn anything. The second highest percentage (25\%) of the total farmers / in-habitants of Charsadda earn between Rs. $10,000-50,000$ or $\sim \$ 87$ to $\sim 435$ from 'commercial activities" while same percentage earn more than Rs. 100,000 or $\sim \$ 870$. Those who do not earn anything are either unpaid family members or work for food. Charsadda's agricultural economy showed greater momentum in last decade, which had a strong impact on the economy of Khyber Pakhtunkhwa. 


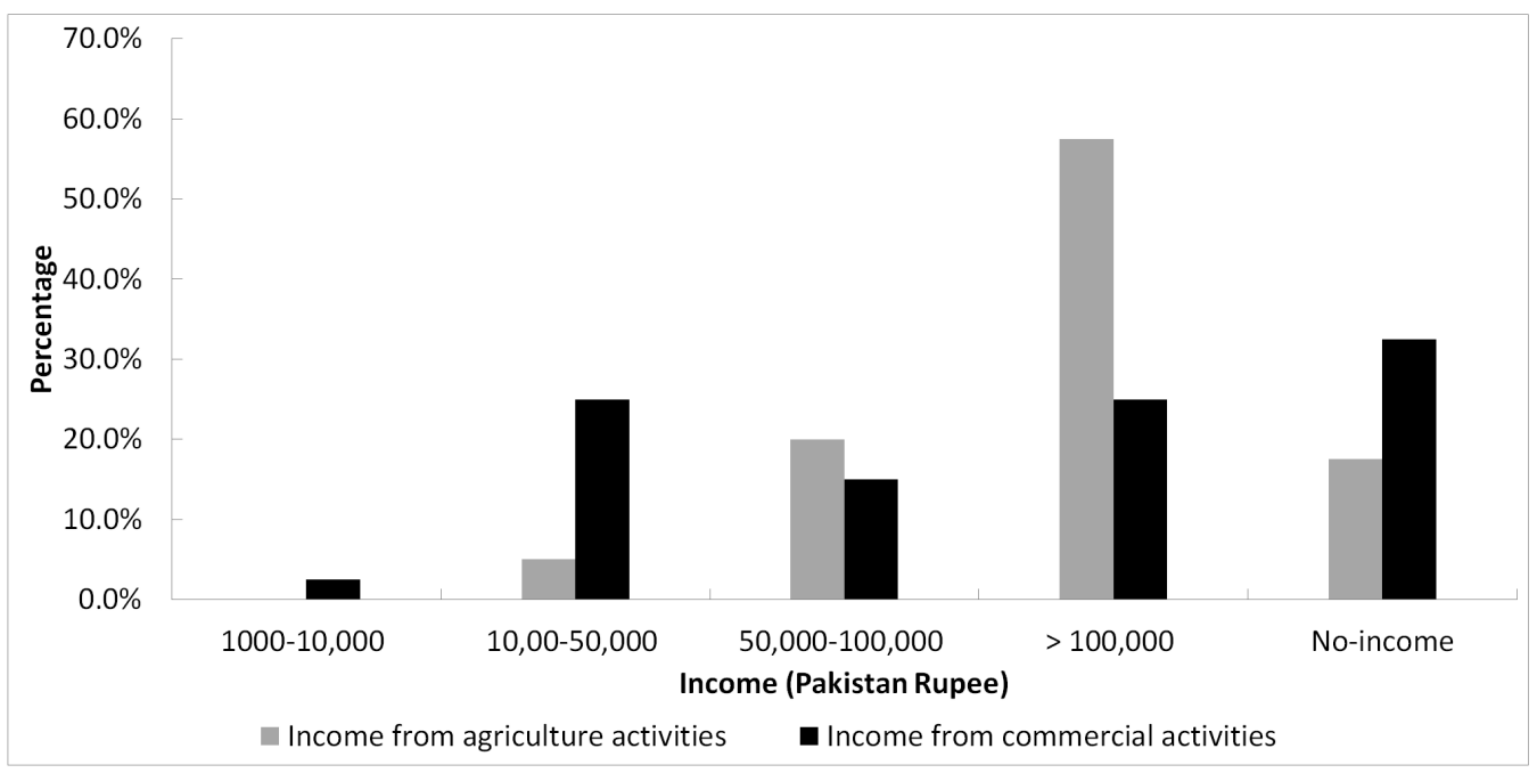

Figure 4. Percentage distribution of income from two main sources (e.g. agriculture and commercial activities). Income is calculated in Pakistani rupee (\$1=115 Pakistani rupees).

\subsection{Land-use diversification based on remote sensing data}

Changes in the extent of land-use categories over a period of 12 years are described through a graph (Figure 5) and a map (Figure 6). The bar graph describes the change in the extent of agriculture, built-up and barren land of four sub-regions (e.g. Naguman, Utmanzai, Niami and Rajjar) of Charsadda district of Khyber Pakhtunkhwa for the years (i.e. 2005 and 2017). The map is an illustration of the changes in the extent of vegetation (e.g. agriculture land, trees) and built-up area (residential / commercial buildings) of the same four sub-regions for the years (i.e. 2005 and 2017). In the year 2005, $85 \%$ of the total land was used for agricultural purposes (e.g. production of variety of crops, vegetables, etc.) while only $12 \%$ accounts for commercial and residential purposes. From 2005 to 2017, the highest diversification in vegetation extent is reported in Naguman region of Charsadda district followed by Rajjar and Niami. However, a slight increase in vegetation extent of Utmanzai is report. An increasing trend in the built-up areas is observed in all the areas of Charsadda, which resulted in a decrease in the agricultural extent. Specifically, in Naguman area, the built-up area has increased by about $>40 \%$ indicating a reduction in agricultural activities. A fraction of land remained barren. Despite declining pattern in the agriculture-covered area, plantation of trees (e.g. eucalyptus trees) has increased in a few villages. Majority of agricultural land in Naguman area has transformed into non-agricultural areas, in which the cultivated land dropped down by $39 \%$ and housing increased up-to $32 \%$. In Niami, the agricultural extent be high (93\%), occupied by vegetation. The highest percentage of barren land and lowest built-up is reported in Niami. Majority of land-area in Rajjar is covered by vegetation (54\%) followed and built up (23\%) and barren land (22\%). 


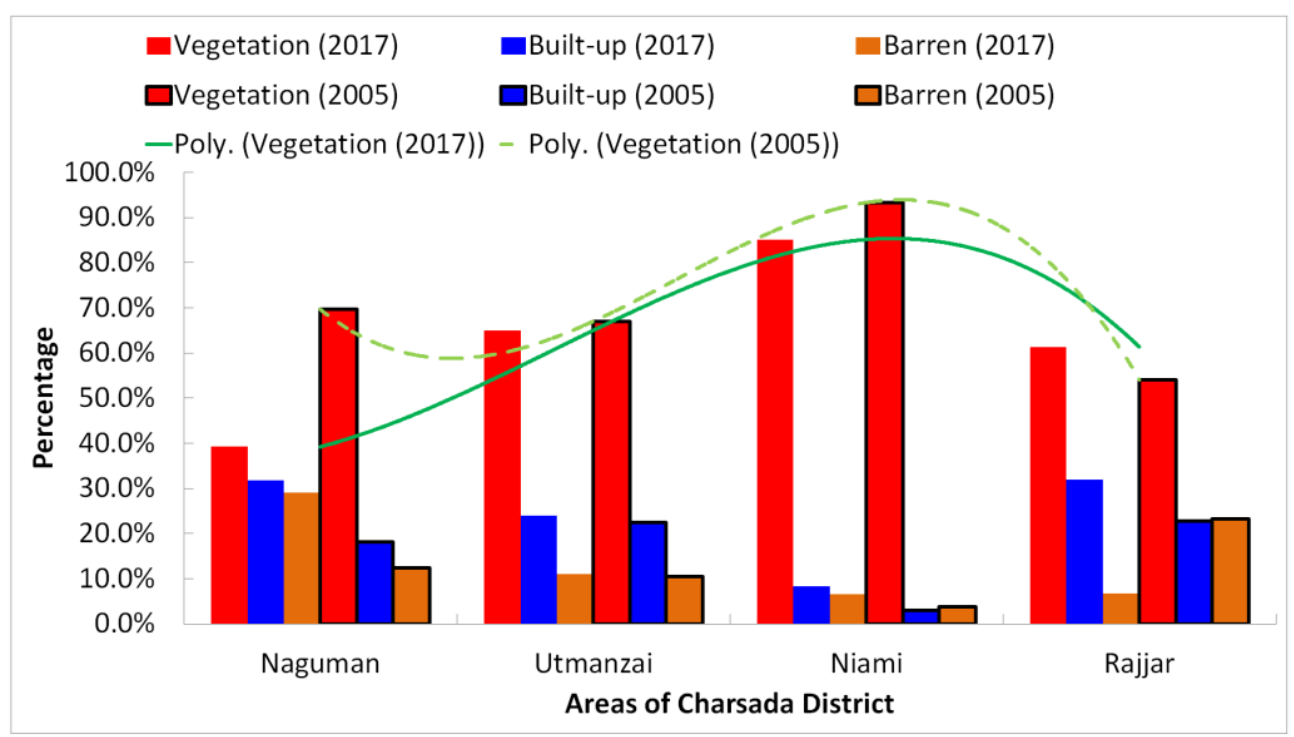

Figure 5. Percentage distribution of diversification in the extent of land-use categories (vegetation, built-up and barren) of four sub-regions (Naguman, Utmanzai, Niami, and Rajjar) over a period of 12 years from 2005 to 2017. Two polynomial (order $=4$ ) trend lines representing changes in vegetation pattern for two years (2005 and 2017)

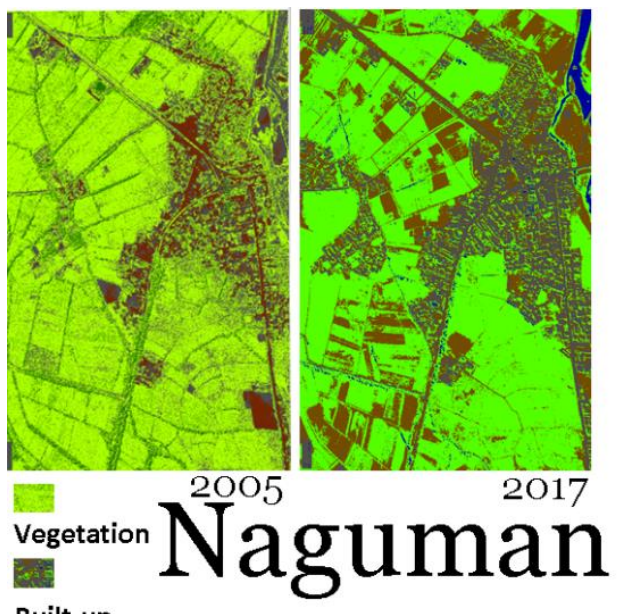

Built-up

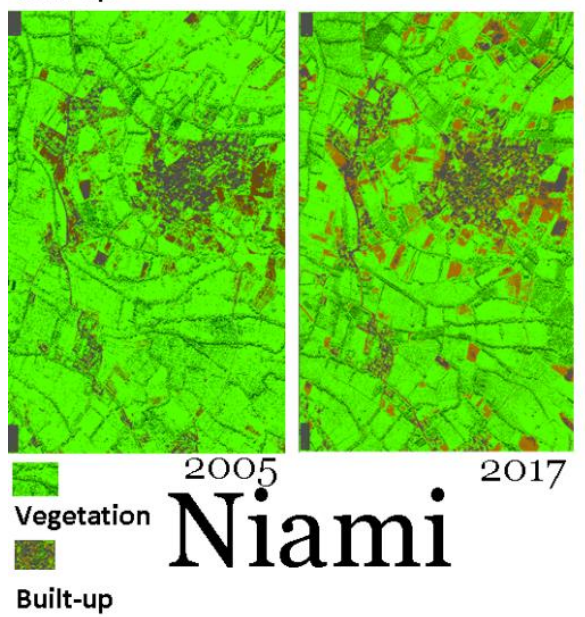

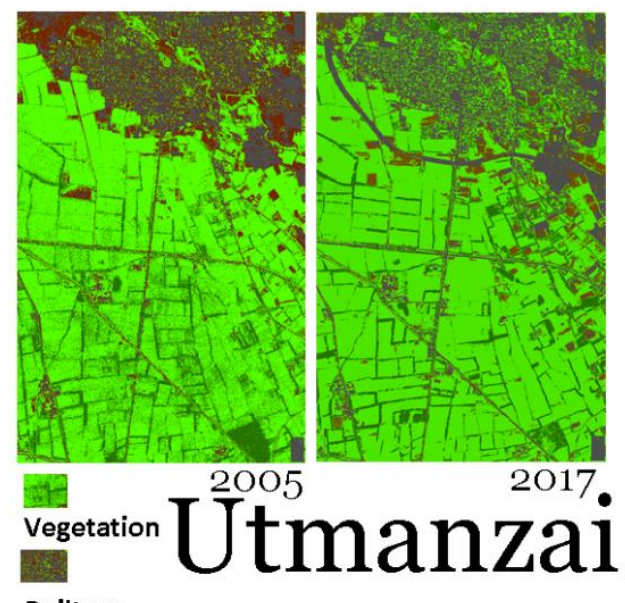

Built-up

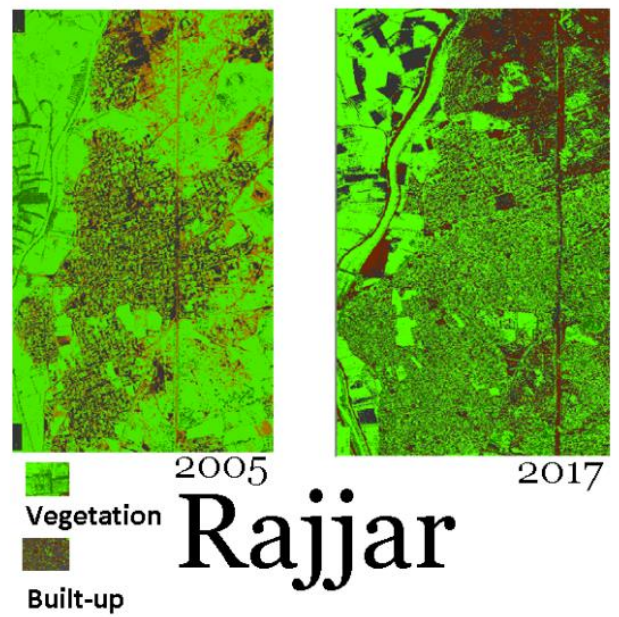

Figure 6. A depiction of land-use diversification based on satellite imagery of available portions of sub-regions of Charsadda district for over a period of 12 years from 2005 to 2017. 


\section{Discussion}

For the last three decades, District Charsadda has gone through rapid changes in population growth. As a result of this population growth along with other factors, land-use changes are evident in areas. Therefore, this study conducted a sample survey to collect, analyze and document landscape related changes. For this purpose, GIS and remote sensing techniques were applied to analyze and cross-verify the results obtained from field-data.

A difference of $\pm 10-15 \%$ between the results obtained from field-data and satellite imagery is reported. One of the reasons for this difference may be due to gauging scale (conversion of income from agriculture products and their corresponding market price) used by farmers, quality of satellite imagery and classification method. Secondly, percentage of land-use change calculated based on a portion of satellite imagery for four sub-regions.

The income of the households of Naguman area is higher as compared to other areas of Charsadda district. The result shows that the urbanization increased drastically in the last decade especially in those areas which are directly connected to the main Charsadda road. As a result of this transformation, the vegetation in all the four sub-regions has decreased. One of the reasons may be rapid growth in urbanization, influx of migrants from rural to urban areas and internally displacement due to conflicts in neighboring FATA. To meet the needs of this huge population, housing societies were established by converting agriculture land into built-up area. As a result of construction of housing societies, urbanization has become a threat to agricultural land and agricultural development.

\section{Conclusions}

In the year - 2017, a huge difference in the land-use is reported within a decade as land used for agriculture production or development declined to $43.1 \%$ from $85 \%$. Specifically, about $85 \%$ of the agriculture land of Naguman area of Charsadda is changed to built-up category tremendously due to increasing commercial activities, migration of people from conflict-prone areas. As a result of this tremendous change, agriculture production drastically decreased in a decade. An increase in urbanization is observed in all the areas of Charsadda. The price of land increased two-fold epically in the areas, which are close to main road (e.g. Charsadda Road). If land-use change continued, then it can be assumed that in future, there would be a shortage of food and water scarcity. Charsadda produces wheat, maize and sugarcane. Therefore, there is a need of an urgent attention by the provincial and federal government to regularize housing societies and slow-down the process of urbanization.

Supplementary Materials: The following are available online at www.mdpi.com/xxx/Questionnaire, Data (in SPSS format).

Author Contributions: Siddique Ullah Baig supervised this work. Additionally, he contributed in Conceptualization, Writing-Review and Editing. Syed Muhammad Jibran Shah, one of the co-authors conducted Field-visit and contributed Methodology, Writing-Original Draft Preparation and Data Analysis. Bahadar Nawab Khattak, one of the co-authors, helped for Funding Acquisition and Administrative matters.

Funding: This research received no external funding.

Acknowledgments: The authors would like to thanks interviewees, who spend their day long with interviewer and provided information / data. Special thanks go to COMSATS University, Islamabad (Abbottabad Campus) for enabling us to carry out this research.

Conflicts of Interest: The authors declare no conflict of interest

\section{References}

1. Azadi, H. Ho, p. Hasfiati L. Agricultural land conversion drivers: A comparison between less developed, developing and developed countries. Land Degradation and Development 2010, 22(6), 596-604. https://doi.org/10.1002/ldr.1037 
2. IPCC Special Report on Land Use, Land-Use Change and Forestry, Inter Governmental Panel on Climate Change, 2000, ISBN: 92-9169-114-3. https://www.ipcc.ch/pdf/special-reports/spm/srlen.pdf.

3. Ahmad, M. Farooq, U. The State of Food Security in Pakistan: Future Challenges and Coping Strategies, Pakistan Institute of Development Economics, Islamabad, 49 (4), 2010, http://www.jstor.org/stable/41428696

4. Zhang, X. Mount, T.D. Boisvert, R.N. Industrialization, urbanization and land use in China, Journal of Chinese Economic and Business Studies 2007, 2:3, 207-224, DOI:10.1080/1476528042000276132.

5. Salghunaa, N.N. Prasada, P.R.C. Kumari, J. A. Assessing the impact of land use and land cover changes on the remnant patches of Kondapalli reserve forest of the Eastern Ghats, Andhra Pradesh, India, The Egyptian Journal of Remote Sensing and Space Science 2018, https://doi.org/10.1016/j.ejrs.2018.01.005

6. Hansen, M. C. Loveland, T. R. A review of large area monitoring of land cover change using Landsat data. Remote Sens Environ 2012, 122, 66-74. https://doi.org/10.1016/j.rse.2011.08.024.

7. Maktav, D. Erbek, F. S. Jurgens, C. Remote sensing of urban areas. International Journal of Remote Sensing 2005, 26(4), 655-659, https://doi.org/10.1080/01431160512331316469.

8. Hooke, R.L. José, F. M. Pedraza, J. Land transformation by humans: A review, GSA Today 2012, 22 (12), DOI: 10.1130/GSAT151A.1.

9. Textor, R. B. Prabhu, P. N. Husain, A. F. A. Deshmukh, M. B. The Social Implications of Industrialization and Urbanization, In Five Studies of Urban Populations of Recent Rural Origin in Cities of Southern Asia, Oxford Printing Works, New Delhi, India, 1956, The Institute of Economic and Social Research Djakarta http://unesdoc.unesco.org/images/ooo6/ooo677/o67784eo.pdf

10. Khan, D. Farooq, W. Mahjabeen, Q. The Agriculture Policy a Ten Years Perspective' for Khyber Pakhtonkhwa (2014-2024G), Agriculture Organization of the United Nations (FAO), 2015, www.fao.org.pk

11. Agric Information (Urdu version). http://agriculture.kp.gov.pk/page/agric_information (accessed on 17.03.2018)

12. Singh, A. Digital change detection techniques using remotely sensed data. International Journal of Remote Sensing 1989, 10, 989-1003.

13. Bruzzone, L. Prieto, D. F. An adaptive semi parametric and context-based approach to unsupervised change detection in multi-temporal remote sensing images. IEEE Transactions on Image Processing 2002, 11(4), 452-466. DOI: 10.1109/TIP.2002.999678

14. Abbas, S. Agriculture in KPK, Agribusiness Pakistan, 2013, http://www.agribusiness.com.pk/agriculture-in-kpk/

15. Samiullah. Expansion of built up area and its impact on urban agriculture in Peshawar Pakistan. PhD, University of Peshawar, Pakistan (2012).

16. Agriculture Statistics, Khyber Pakhtunkhwa, 2015, http://kp.gov.pk/uploads/2016/04/2015.PDF (accessed 29.01.2017)

17. Chavare, S. Application of Remote Sensing and GIS in Landuse and Land Cover Mapping of SubWatershed of Wardha River Basin, Proceedings of National Conference on Development \& Planning For Drought Prone Areas. ISBN- 978-93-5174-933-2 (English) 978-93-7174-934-9 (Hindi/Marathi)

18. Strielko, I. Pereira, P. The benefits of GIS to land use planning, 2014. Geophysical Research Abstracts, 16, EGU2014-15813-2, 2014 EGU General Assembly 2014.

19. Pakistan Bureau of Statistics, Khyber Pakhtunkhwa, http://www.pbs.gov.pk/pco-kpk-tables?page=1 (accessed 2018-04-23). 